\title{
Study on the effect of samplers on the disturbance of dredger- filled soil structure by numerical simulation layering method
}

\author{
Zhijie $\mathrm{Li}^{1}$, Jing Song ${ }^{1,2,3,}$, Zhou Zhao ${ }^{1}$, Shouying Yang ${ }^{1}$, Jiansen Huang ${ }^{1}$ and Weibiao Huang ${ }^{1}$ \\ ${ }^{1}$ School of Earth Sciences and Engineering, Sun Yat-Sen University, Guangzhou 510275, China \\ ${ }^{2}$ Guangdong Provincial Key Lab of Geodynamics and Geohazards, Guangzhou 510275, China \\ ${ }^{3}$ Guangdong Provincial Key Laboratory of Geological Processes and Mineral Resource Exploration, Guangzhou 510275, China
}

\begin{abstract}
Through the use of the particle flow software simulation, the influences on the microscopic dynamic properties of high viscosity soft soil caused by the inner diameter, cut angle and wall thickness of the samplers were studied with the example of the dredged mud. The motion behavior of the inflection point of particle characteristics was compared in seven soil samples by dividing the soil layers. The results show that a convective displacement field of the soil particles is formed at the bottom, and the particles above the convection are mainly subject to tensile expansion while the particles below the convection are mainly compressed and contracted, which result in the regular changes in porosity and bending deformation of the soil layers. There is a synergistic relationship between the intersection of the porosity curve and the initial porosity curve and the convective position of the particle displacement field. There is a characteristic inflection point in the interlayer particle displacement with the soil layers behave as a bending deformation. The particle disturbance between the inflection points is not obvious and the particle disturbance outside the inflection points is larger. The deformation feature can be fitted to a rotating paraboloid with the lower opening and the disturbance of the seven groups soil samples can be assessed initially by the a value of the surface equation. The line connecting the inflection points of the interlayer features can be refitted to a paraboloid of rotation. The ratio of the volume of the paraboloid to the volume of the soil sample can be used to evaluate the originality of the soil sample.
\end{abstract}

\section{Introduction}

With the development of the global super-large urban agglomeration, the shortage of land resources in coastal cities has become increasingly acute [1].In order to alleviate the shortage of land resources, the dredged mud of the channel has been widely applied to the land reclamation projects through treatment [2].The evaluation of physical and mechanical properties of hydraulically dredged mud is the basis of engineering design. The more accurate the properties are evaluated, the greater the economic benefits of the projects [3]. The damage of soil sample structure caused by the penetration of soil samplers is the main factor affecting the physical and mechanical properties of soil.

In recent years, many scholars have studied soil disturbance caused by sampling penetration. Clayton et al. [4] used the finite element method to predict the strain path of the soil element at the center line of the sampling pipe, and the results verified that the strain path method proposed by Baligh [5]is effective to evaluate the degree of penetration disturbance. Tan et al. [6] used the Japanese thin-wall piston sampler and Shelby sampler to obtain the marine soft clay sample in Singapore, and the changes of shear strength of the two groups samples were obtained by triaxial unconfined compression test and undrained compression test. Jiang et al. [7] studied the influence of the inner diameter of the thin-wall sampler on the disturbance, and the disturbance was evaluated by volume compression method and volume strain method under the self-weight stress. The result shows that the quality of soil samples from large diameter pipe mouth is better than that from small diameter pipe mouth and the soil samples from large diameter pipe mouth ensure reliability of laboratory test results. Qin et al. [8] obtained the theoretical solution of the soil squeezed by tube wall by using spherical expansion theory. Eyre [9] calculated the strain path of the central axis of the soil sample during the penetration of the sampler by particle image velocimetry, and compared it with the existing research and the strain prediction of the numerical model. The result shows that the strain path obtained by this method has a certain correlation with the theoretical solution. According to the deformation and strain solution calculated by the expansion of spherical cavity in the semi-infinite space, Wu et al. [10] established the strain formula during the process of the soil sampler penetrating into soil. The results show that the closer the soil is to the pipe wall, more disturbed it is. Yan et al. [11] proposed a visual method to study the disturbance inside and outside the pipe wall during the penetration.

Corresponding author: songj5@mail.sysu.edu.cn 
The results show that the disturbance in the center line of the pipe is very small, and the affected area outside the pipe is 1.5 times larger than the diameter. Compared the laboratory test and field test, Vuthy et al. [12] analyzed the influence of geometric size on soft clay disturbance by means of control variable. The results show that the cutting angle and wall thickness are most sensitive to the disturbance. The smaller the cutting angle and the thinner the wall, the more undisturbed the soil collected. Liu et al. [13] proposed a surface slope method to describe the stratification of lunar soil samples. This method can quantitatively distinguish the boundary between the small disturbance and the damaged part of each layer.

The hydraulically dredged mud has the characteristics of high sensitivity, high water content, low bearing capacity and fine particle size. The penetration of the soil sampler is extremely sensitive to the disturbance of the soil. The soil is a good carrier for studying the originality of soil sample. Based on particle flow software, this paper analyzes the micro mechanism of penetration disturbance while the sampling of hydraulically dredged mud. On the basis of numerical simulation test, it was studied that the influence of internal diameter, cutting angle and wall thickness on micro-dynamic characteristics of soft soil with high viscosity. Through the method of stratification, the movement behavior of the characteristic inflection point of the particles in different groups is compared quantitatively, which help for the design and optimization of special soil sampler.

\section{Establishment of particle flow model}

\subsection{Simulation of static water environment}

Whether the model accurately reflects the physical and mechanical characteristics is the key to the success of the simulation test. For the model of hydraulically dredged mud, whether the moisture content is considered or not will greatly affect the authenticity of the model. Through a series of indoor grading vacuum preloading tests, Song [14] obtained the moisture content of the hydraulically dredged soil in Dalian, Tianjin and other places is about $120 \%$. The soil is stable in the static water environment, and the particles are mainly affected by the floating force, gravity and the pressure of overlying soil [15], as shown in Figure 1. In order to simplify the calculation, this paper assumes that the penetration process does not cause excessive pore water pressure in the soil, and the particles do not percolate, then the equation is:

$$
F=\rho g V
$$

where $F$ is the floating force of water, $\rho$ is the density of water, $g$ is the acceleration vector of gravity, $V$ is the volume of water discharged by particles. $V$ of the soil in saturation is equal to the volume of the particle itself.

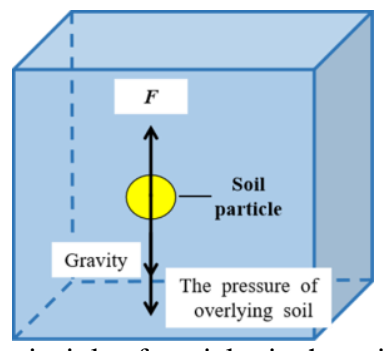

Fig. 1 Coupling principle of particles in the quiet water

\subsection{Calibration of model parameters}

The accuracy of particle interactions directly affects the simulation results when the sampler is inserted. Lei [16]and Song [14] compared the granulometric composition of hydraulically dredged mud in coastal cities of China through field sampling analysis, and selected newly-dredging areas in Dalian, Tianjin and other places for microscopic parameter study, as shown in Table 1-2. In addition, when the ratio of the overall size of sampler to the average particle size of the particles is greater than 30 , the size effect can be neglected [17]. Therefore, in order to improve the calculation efficiency, the particle size control interval in the numerical model is set to $[1,1.5] \mathrm{mm}$ and obey uniform distribution. After the model becomes stable and the side wall command is cancelled, the fixed boundary particles to better fit the effect between actual particles, as shown in Figure 2.

Table 1 Grain size distribution properties of hydraulically dredged mud [14][16]

\begin{tabular}{ccccc}
\hline \multicolumn{1}{c}{ Mass percent of each grain group/\% } & $\begin{array}{c}\text { The } \\
\text { effective } \\
\text { particle } \\
\text { size }\end{array}$ & Zone \\
\cline { 1 - 3 } $0.1 \sim 0.07$ & $0.075 \sim 0.0$ & $0.005 \sim 0.0$ & & \\
5 & 05 & 02 & $0.003 \mathrm{~m}$ & DaLian/ \\
$\mathrm{mm}$ & $\mathrm{mm}$ & $\mathrm{mm}$ & $\mathrm{m}$ & TianJin \\
\hline 1 & 39 & 60 & & \\
\hline
\end{tabular}

Table 2 Mesoscopic parameters of particles [14]

\begin{tabular}{cc}
\hline Parameters & Value \\
\hline Friction Coefficient $/ \mu$ & 0.3 \\
Density $/\left(\mathrm{kg} / \mathrm{m}^{3}\right)$ & 2500 \\
Initial Void Ratio & 3 \\
Damping Coefficient & 0.7 \\
Normal Stiffness $/(\mathrm{N} / \mathrm{m})$ & $1.0 \mathrm{E}+3$ \\
Shear Stiffness $/ /(\mathrm{N} / \mathrm{m})$ & $1.0 \mathrm{E}+3$ \\
Normal Bond Strength $/ /(\mathrm{N} / \mathrm{m})$ & $2.0 \mathrm{E}+5$ \\
Shear Bond Strength $/(\mathrm{N} / \mathrm{m})$ & $2.0 \mathrm{E}+5$ \\
\hline
\end{tabular}




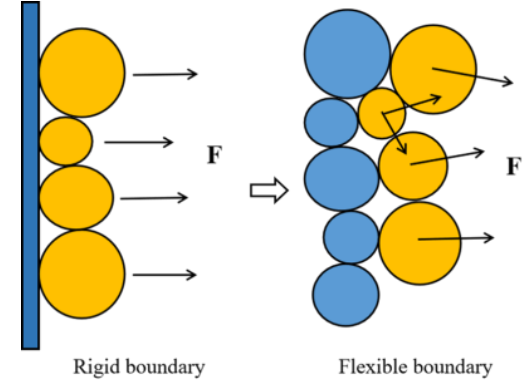

Fig. 2 The schematic diagram of boundary coupling

\section{Model of the soil sampler's penetra- ti} on

\subsection{Model parameter scheme}

In this paper, the variable-controlling method is used to analyse the influence of internal diameter, wall thickness and cutting angle of soil sampler on soil disturbance, and the friction coefficient [18-19] and penetration speed [1920] of the model are calibrated with reference to relevant papers. In order to improve the calculation efficiency, the soil sampler was simplified into a cylindrical tube wall with a lower opening in the model, and seven simulation tests were carried out on the soil sampler with different internal diameters, cutting angles and wall thickness, as shown in Table 3. Among them, the series $(6,2,50)$ represents the soil sampler model with a cutting angle of $6^{\circ}$, a wall thickness of $2 \mathrm{~mm}$ and an inner diameter of $50 \mathrm{~mm}$. In the same way, the meaning of the other six groups of numbers can be obtained.

Direct-pushing penetration is one of the main methods of soft clay sampling. In the system program, the tube walls of the soil sampler are constructed by a combination of rigid walls, which are identified as rigid boundaries. By applying a certain amount of normal load to the rigid boundary, the process of straight penetration into the soil can be approximately equivalent, and the penetration velocity can be estimated by the magnitude of the load. The speed equation is:

$$
\left\{\begin{array}{l}
\dot{u_{n}^{w}}=G \Delta \sigma \\
G=\frac{\alpha A}{k_{n}^{(\mathrm{W})} N_{c} \Delta t}
\end{array}\right.
$$

where $\dot{u}_{n}^{W}$ is the penetration speed of the boundary wall, $\Delta \sigma$ is stress value of unit time step, $G$ for servo adjustment coefficient, $A$ is the area of the border wall, $\alpha$ is the stress release factor, generally takes $0.5, k_{n}^{(W)}$ is the average contact stiffness, $N_{c}$ is the number of contacts between the boundary wall and the particles, $\Delta t$ is unit time step.

Table 3 Microscopic parameters of soil sampler

\begin{tabular}{cccccc}
\hline Num & Cut- & Wall & Inner & Penetration & Friction \\
-ber & ting & Thick & Dia- & Coeffi- \\
& Angle & -ness & meter & Speed & cient \\
\hline
\end{tabular}

\begin{tabular}{|c|c|c|c|c|c|}
\hline & $1^{\circ}$ & $/ \mathrm{mm}$ & $/ \mathrm{mm}$ & & \\
\hline $\begin{array}{c}(6,2, \\
30)\end{array}$ & 6 & 2 & 30 & & \\
\hline $\begin{array}{c}(6,2, \\
50)\end{array}$ & 6 & 2 & 50 & & \\
\hline $\begin{array}{c}(6,2, \\
70)\end{array}$ & 6 & 2 & 70 & & \\
\hline$(30,1$ & & & & & \\
\hline $\begin{array}{c}.5,50 \\
)\end{array}$ & 30 & 1.5 & 50 & $1.0 \mathrm{~cm} / \mathrm{s}$ & 0.36 \\
\hline $\begin{array}{c}(30,2 \\
, 50)\end{array}$ & 30 & 2 & 50 & & \\
\hline $\begin{array}{c}(30,5 \\
, 50)\end{array}$ & 30 & 5 & 50 & & \\
\hline $\begin{array}{c}(90,2 \\
, 50)\end{array}$ & 90 & 2 & 50 & & \\
\hline
\end{tabular}

\section{Structural disturbance analysis}

\subsection{Formation of particles convection field}

In the soil of semi-infinite space, due to the limitation of the horizontal displacement direction of the soil sample by the pipe wall, the soil is squeezed by the soil when the soil sampler penetrates, and a stable vortex-like displacement field is formed near the pipe wall. A scattering displacement field is formed in the middle of the soil sample. As the penetration progresses, the scattered displacement fields on both sides of the tube wall are interlaced with each other in the soil sample, and gradually become a convective displacement field with unstable direction. The particles in the upward direction of displacement cause the stress release in the upper soil, the volume expansion and the force between the particles are reduced to form a weak chain region, in which the porosity increases; the particles with the downward direction of the displacement cause the compressive stress increases in the lower soil, the volume compresses and the force between the particles increases to form a strong chain region, in which the porosity decreases. And the position of convection changes with the penetration depth and size parameters.

Through the simulation test of the above seven groups, as shown in Fig. 3-4. The displacement field above the convection shows tensile expansion as a whole, while the displacement field below the convection shows compression contraction. It results in the regular change of soil sample porosity and the bending deformation of layering, as shown in Fig. 5-6
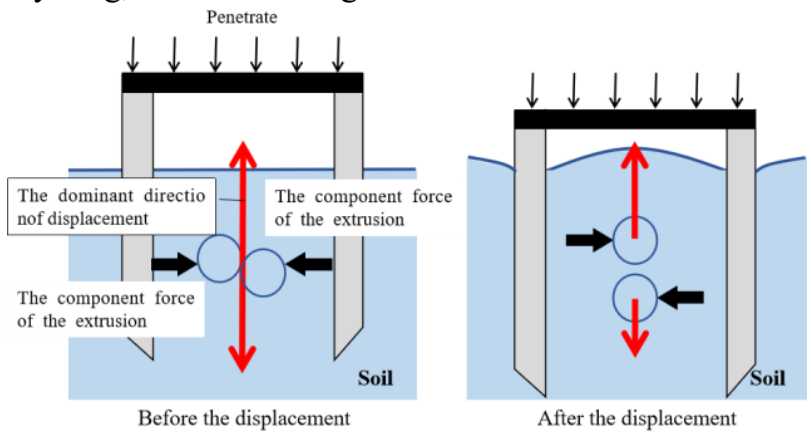

Fig. 3 The principle of force formed by convection displacement field 

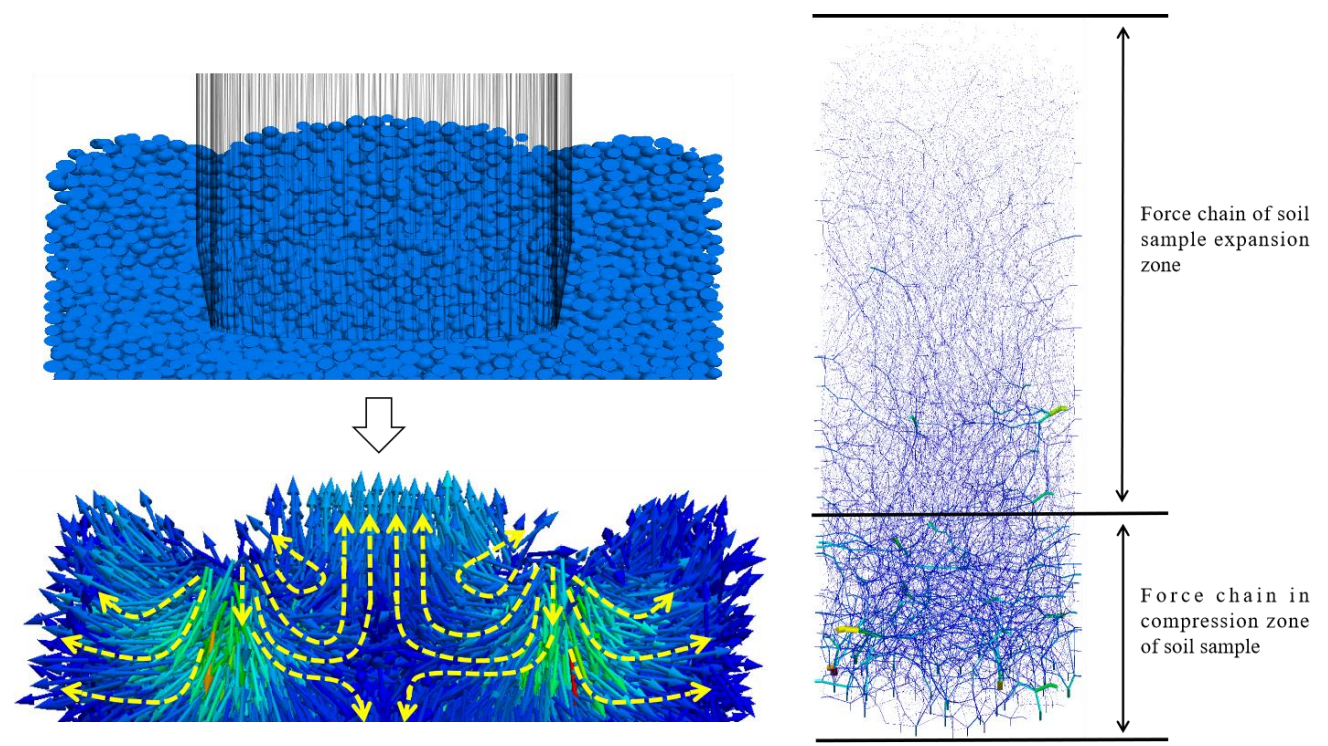

Fig. 4 The schematic diagram of Convective displacement field

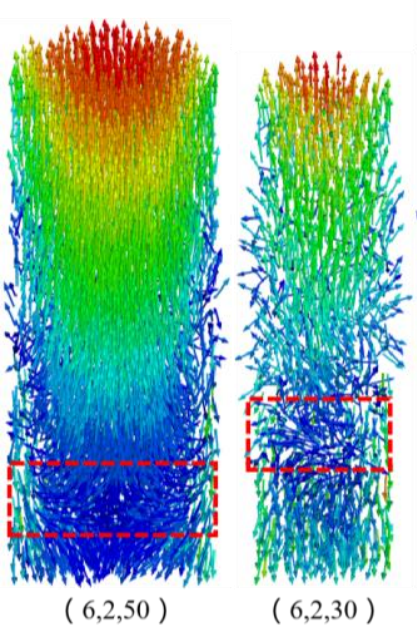

\section{2 porosity analysis}

In seven times of test simulation, there is a linearly positive correlation between the porosity of each group and the length of soil samples, as shown in Fig. 6. When the control variable is the inner diameter, compared with the initial state, the porosity increment of soil sample obtained by the soil sampler with the inner diameter of $30 \mathrm{~mm}$ is the most obvious, and the soil sample is in the expansion state as a whole. The porosity of $50 \mathrm{~mm}$ and $70 \mathrm{~mm}$ soil samples are transitive around $15 \mathrm{~mm}$, and the porosity of the part below $15 \mathrm{~mm}$ is smaller than the initial porosity. It indicates that the particles in this area are compressed, and vice versa. The overall change of porosity of soil samples with diameters of $50 \mathrm{~mm}$ and70 $\mathrm{mm}$ is not obvious, which indicates that the smalldiameter soil sampler has a greater impact on the soil structure. When the control variable is cutting angle, compared with the initial state, the soil sample with a cutting angle of $90^{\circ}$ has the largest change in porosity,

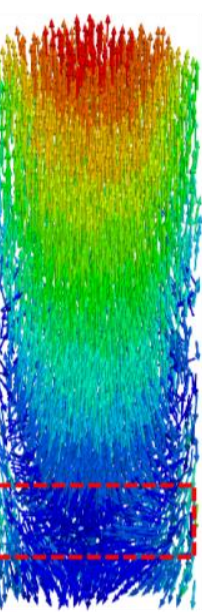

$(30,1.5,50)$

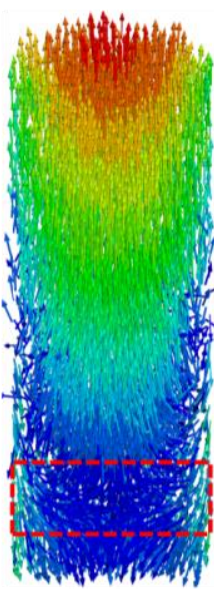

$(30,2,50)$

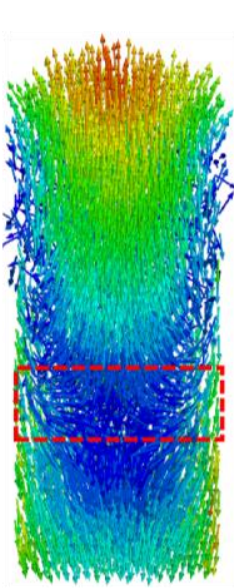

$(30,5,50)$

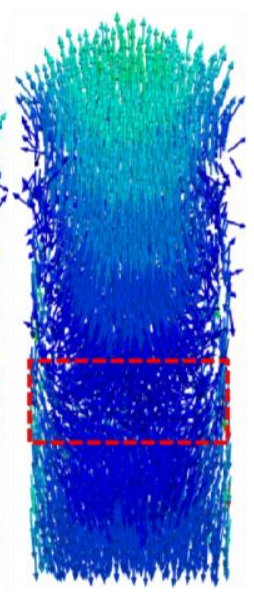

$(90,2,50)$

Fig. 5 Displacement fields of soil samples and the soil samples are transitive at $25 \mathrm{~mm}$. The porosity of soil samples corresponding to the angle of $6^{\circ}$ and $30^{\circ}$ was transitive around $10 \mathrm{~mm}$, and the porosity of the two samples was not significantly changed. It indicates that the large-angle soil sampler has a slightly greater influence on the soil structure than the small angle soil sampler. When the control variable is wall thickness, compared with the initial state, the porosity of soil samples obtained by the soil sampler with a thickness of $5 \mathrm{~mm}$ has the largest change range and the transition occurs around $20 \mathrm{~mm}$. The porosity of soil samples corresponding to the thickness of $1.5 \mathrm{~mm}$ and 2 $\mathrm{mm}$ are transitive around $10 \mathrm{~mm}$, and their relative change trends are more consistent. It indicating that the thick-wall soil sampler has a greater impact on the soil structure. In addition, it can be inferred from Fig. 6 that there is a strong synergy between the transition point and the convective position of the soil displacement field. 

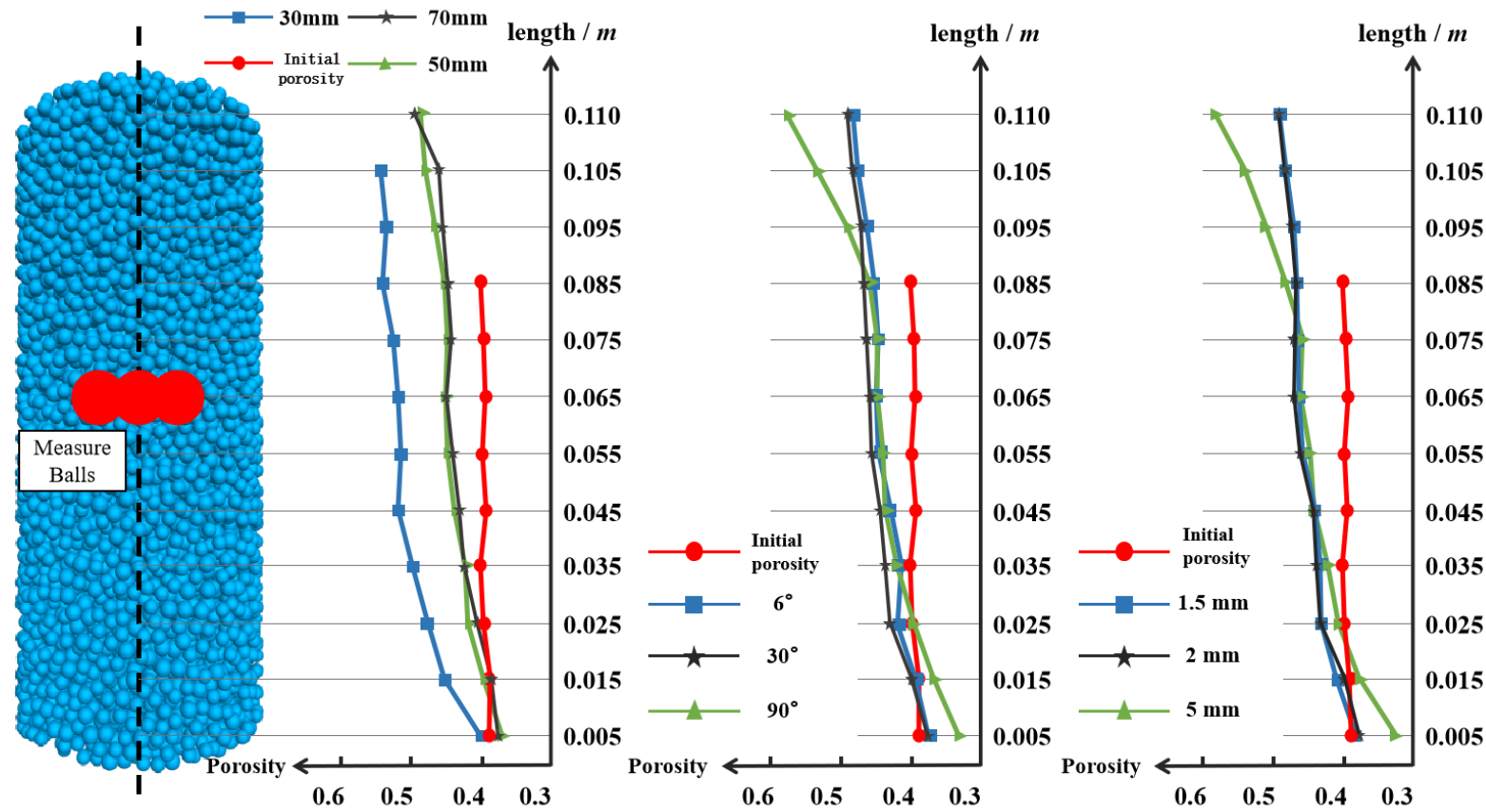

Fig. 6 The curve of samples' vertical porosity

\subsection{Layer disturbance analysis}

\subsubsection{Analysis of bedding characterization}

The analysis of soil sample layering is the focus of engineering geological investigation, but due to the limitation of observation, some scholars put forward the numerical simulation method to analyze soil sample layering [18,21]. Through particle flow software, Fig. 7 shows the results of penetration after initial soil stratification. It shows the same bedding disturbance characteristics of seven groups. That is, the displacement of the particles between the layers is an inverted Ushaped distribution, which appears as a curved surface in a three-dimensional space. The change trend of the particles in the middle is smoother, while the displacement of the particles on both sides is exponential, and the structure is obviously destroyed. There are characteristic inflection points in the central smooth area and the both sides of the destruction zone. The smoothing zone between the inflection points and outside the inflection point is the destruction zone. For this deformation feature, its curved shape can be fitted as a rotating paraboloid with the opening facing down, as shown in Fig. 8. The fitting equation is designed as follows:

$$
\frac{x^{2}}{a^{2}}+\frac{y^{2}}{b^{2}}+c=-z
$$

where $x, y$ and $z$ are spatial coordinates of particles, $a$ and $b$ are curved surface shape fitting coefficients with $a$ $\approx b$, and $c$ are curved surface depth fitting coefficients.

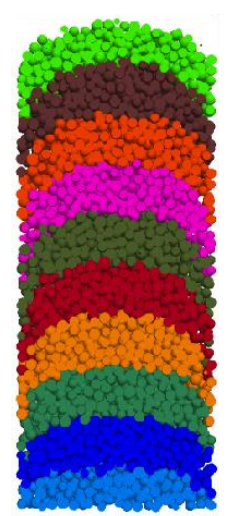

$(6,2,50)$

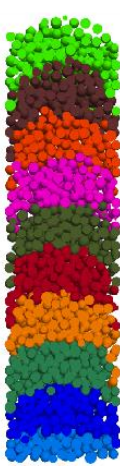

$(6,2,30)$

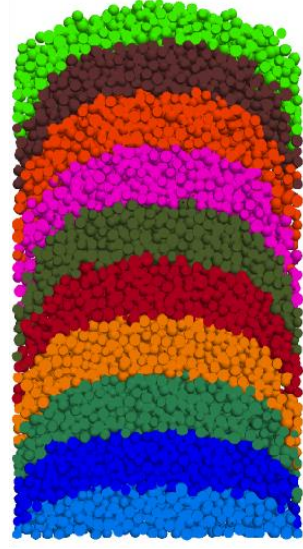

$(6,2,70)$

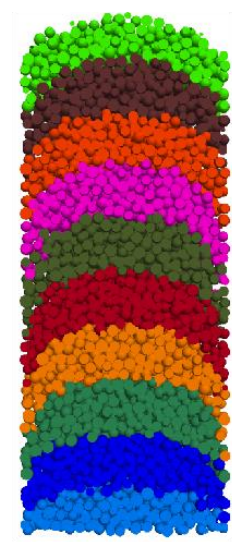

$(30,1.5,50)$

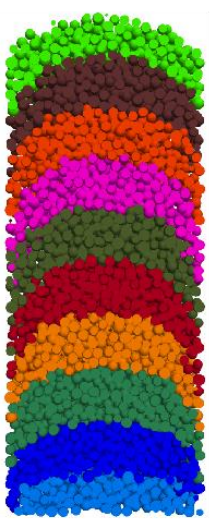

$(30,2,50)$

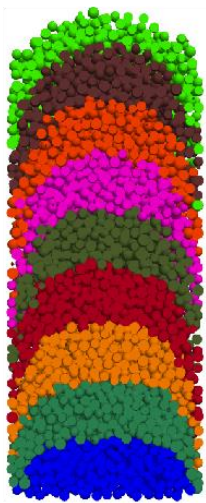

$(30,5,50)$

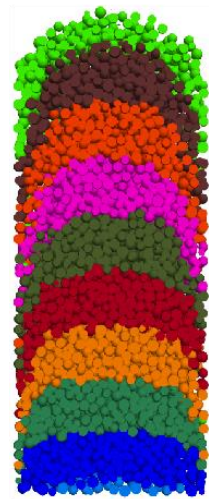

$(90,2,50)$

Fig. 7 Sectional views of $x O z$ surfaces of seven groups' soil samples 


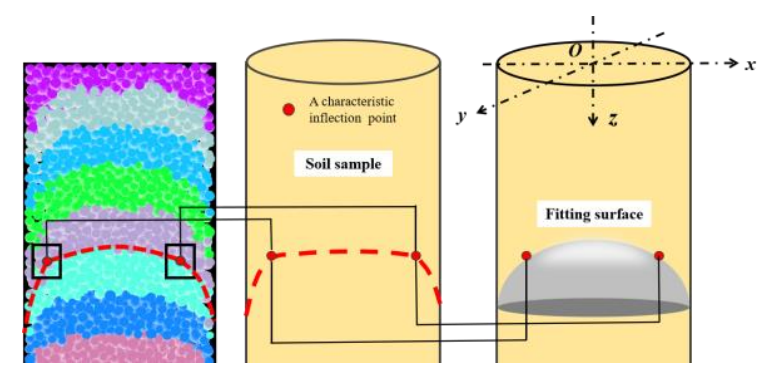

Fig. 8 The schematic diagram of rotating paraboloid In order to facilitate calculation, the origin coordinate is set at the center of the top surface of the soil sample in this paper, and the intersection line between the surface and the curved surface in the $x O z$ plane is intercepted for analysis. The surface is symmetric about $z$-axis and its simplified equation is:

$$
\frac{x^{2}}{a^{2}}+c=-z
$$

According to equation (4), the coordinates of inflection point in the plane are substituted into the fitting equation to output a value along the depth of the soil sample, and the relationship between shape factor and the depth of the soil sample is obtained, as shown in Fig. 9. The $a$ value of each group is linearly negatively correlated with the depth, and the magnitude of $a$ value can indirectly reflect the disturbance degree of soil samples: the smaller $a$ value is, the smaller the interval between characteristic inflection points in the same layer, the fewer the particles in the smooth area, the more obvious the bedding deformation, and the lower the undisturbance of soil samples; otherwise, the higher the undisturbance of soil samples.

When the control variable is wall thickness, the $a$ value of the three groups are stable in the interval [0.04, 0.08], and the larger values are concentrated in the lower half of the soil samples. The curves of the three groups have a small change range, among which the curve value corresponding $1.5 \mathrm{~mm}$ is larger than $2 \mathrm{~mm}$ and $5 \mathrm{~mm}$, and the soil samples have better undisturbance. When the control variable is the cutting angle, the curve value of the three groups is stable in the interval [0.04, 0.07], and the larger value is concentrated in the part below the depth of 0.06 meters. The curve of the three changes is not obvious, and it is impossible to directly discriminate the optimal value of the soil sample corresponding to the set of variables. When the control variable is inner diameter, the curve values of the three groups change in a large range with distinct layers, and the corresponding curve values of $30 \mathrm{~mm}, 50 \mathrm{~mm}$ and $70 \mathrm{~mm}$ increase successively. It can be preliminarily judged that the undisturbance of the soil samples corresponding to 70 $\mathrm{mm}$ inner diameter is better than the other two.
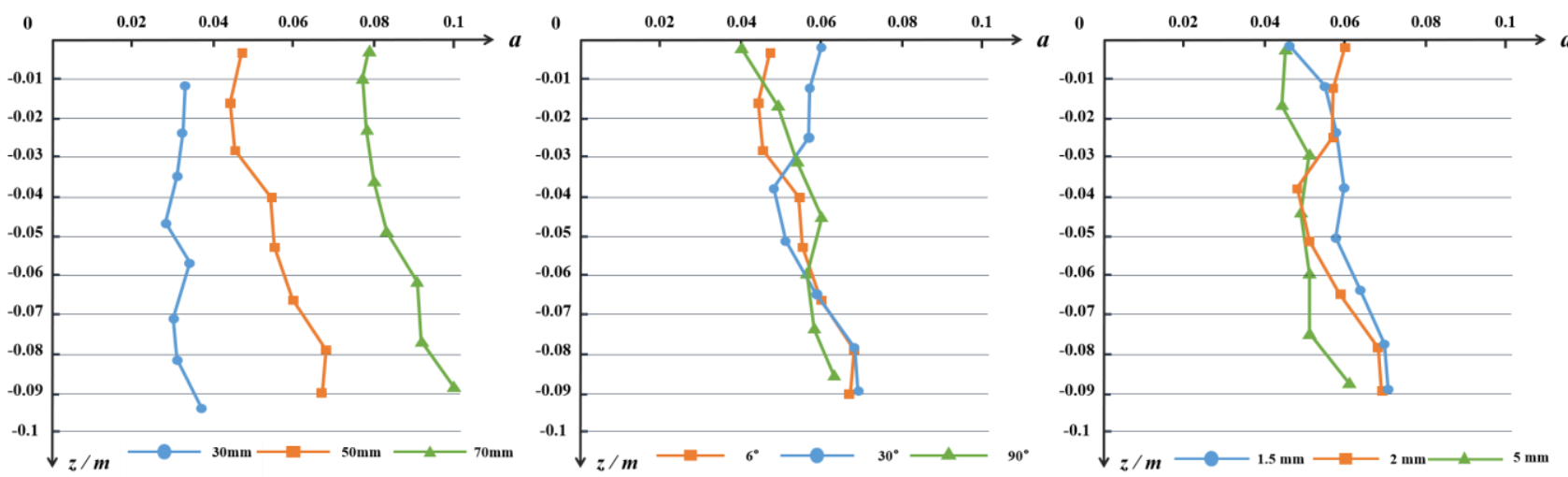

Fig. 9 The relationship between the fitting surface coefficient $a$ and the soil sample depth

\subsubsection{Analysis of bedding structure}

In the $x O z$ plane, smooth curves are used to connect the characteristic inflection points of each layer in turn, and the parabola passing through the origin can be fitted again, as shown in Fig. 10. The fitting equation is:

$$
\frac{x^{2}}{a_{1}^{2}}+\frac{y^{2}}{b_{1}^{2}}=-z
$$

where $a_{l}$ and $b_{l}$ are shape fitting coefficients and $a_{l} \approx$ $b_{1}$. By rotating multiple angular slices along the $\mathrm{z}$-axis, values of multiple groups of the same soil sample can be calculated, and the more groups there are, the closer the average value is to the actual value. The modified surface equation is shown in formula (6):

$$
\frac{x^{2}}{\bar{a}_{1}^{2}}+\frac{y^{2}}{\bar{b}_{1}^{2}}=-z
$$

The surface approximately defines the boundary between the disturbance area and the destruction area of the soil sample, as shown in Fig. 11. The soil outside the surface is the destruction zone, and the soil inside the surface is the micro-disturbed zone. The volume of the surface can be obtained through the volume integral of formula (6). And then the ratio of the volume of the surface to the total volume of the soil sample is a number greater than zero and less than one (assuming that the volume of the soil sample is equal to the volume of the cavity of the inner wall of the soil sampler). The calculation formula is shown in (7): 


$$
\left\{\begin{array}{l}
V_{\text {surface }}=\pi \int_{z_{1}}^{z_{2}}\left(-\bar{a}_{1}^{2} z\right) d z \\
\frac{V_{\text {surface }}}{V_{\text {soil }}} \times 100 \%=R
\end{array}\right.
$$

where $z_{l}$ and $z_{2}$ is the endpoint value of the soil sample in the $x O z$ plane, $V_{\text {surface }}$ is the volume of the surface, $V_{\text {soil }}$ is the total volume of soil samples, $R$ is the volume percentage of both. The closer the $R$ value is to $100 \%$, the better the soil layer retention characteristics and the lower the degree of structural damage.
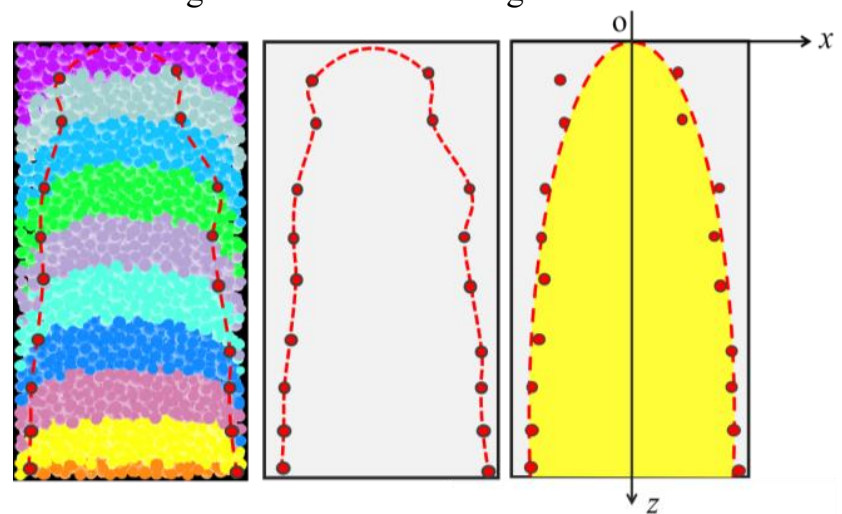

Fig. 10 The schematic diagram of structurally fitting surface

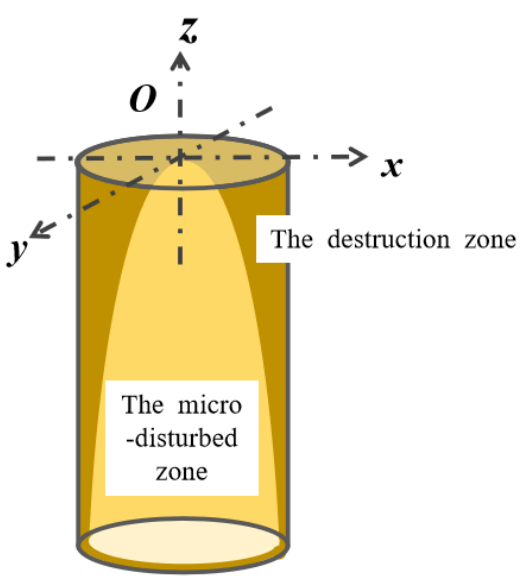

Fig. 11 The soil sample disturbance of partitions

The above seven groups of variables were converted into the relation between shape factor and $\mathrm{R}$ by the method of definite integral, as shown in Fig. 12. The average slope of the curves of the three groups, including inner diameter, cutting angle and wall thickness was 1.8, 21.6 and 21.3 respectively. This shows that both largediameter and thin-walled soil sampler can collect hydraulically dredged mud with good bedding retention characteristics, but the change of inner diameter does not affect the soil sample bedding much as the cutting angle and wall thickness. The change of the cutting angle and the wall thickness can have a great influence on the soil layering, and the wall thickness can be changed to obtain the soil sample with better layering retention characteristics.

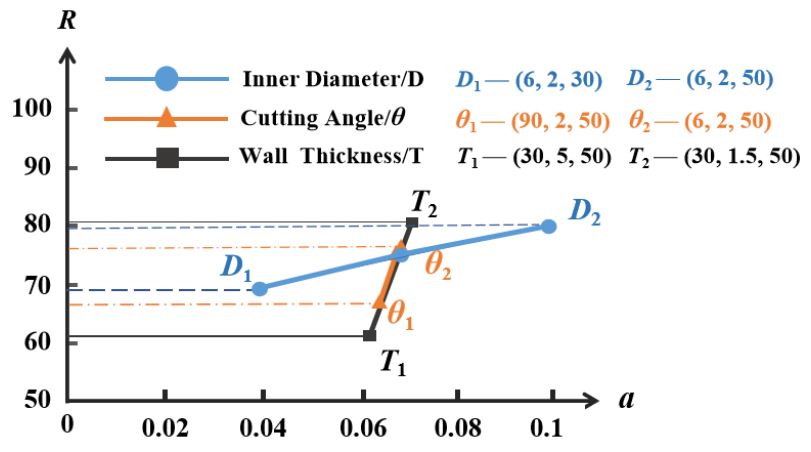

Fig. 12 Relation chart between shape factor $a$ and $R$ of samples

\section{Conclusion}

This paper based the numerical simulation test of particle flow and analyzed the influence of the geometric size of the soil sampler on the disturbance of hydraulically dredged mud samples. The deformation characteristics of soil microstructure are analyzed and quantified by using the variable-controlling method. The main conclusions are as follows:

(1) Due to the limitation of the horizontal displacement direction by the pipe wall, the particles are pressed against each other when the soil sampler penetrates, and a vortex-like displacement field is formed near the pipe wall, and a scattering displacement field is formed in the middle of the soil sample and gradually changes into a convective displacement field with the penetration. The particles above the convection zone are mainly subjected to tensile expansion, while the particles below the convection zone are mainly compressed and contracted, which results in the regular changes of porosity and the bending deformation of layering.

(2) the porosity and length of soil samples corresponding to each group are positively linearly correlated. Among them, the $30 \mathrm{~mm}$ inner diameter, the $90^{\circ}$ cutting angle and the $5 \mathrm{~mm}$ wall thickness correspond to the most obvious variation of the porosity of the soil sample, and have the greatest influence on the soil sample structure. It is recommended to reduce the size during the actual sampling process. Moreover, there is a strong synergy between the intersection of the size parameter curve and the initial state curve and the convection position of the displacement field.

(3) The layering of soil samples is characterized by downward bending deformation, which is approximately inverted $\mathrm{u}$-shaped from the macroscopic perspective. There is a characteristic inflection point in the intergranular particle displacement behavior, and the particle disturbance behavior between the inflection points is not obvious. On the contrary, the particle disturbance behavior is large outside the inflection points. This deformation feature can be fitted as a rotating paraboloid with a downward-facing opening, and the shape coefficient of the surface equation has a linearly negative correlation with the depth of the soil sample. The larger a value is, the smoother the surface is, the smaller the bedding deformation is, and the better the undisturbed soil sample is. 
(4) the line of characteristic inflection points between layers can be fitted as a structural disturbance surface, and the ratio of the volume of the curved surface to the volume of the soil sample can be used to evaluate the degree of disturbance of the soil sample structure. Among them, the large-caliber and thin-walled soil sampler can collect hydraulically dredged soil with good bedding retention characteristics; The effect of cutting angle and wall thickness on the soil layering is larger than the inner diameter. Through the change of the wall thickness, the soil sample with the best layer retention property can be collected.

\section{References}

1. Y. L. Zheng, R. J. Zhang, J. J. Zheng, et al., "Experimental study on flocculation-solidification combined treatment of hydraulically dredged mud at extra high water content", Rock and Soil Mechanics, vol.08, pp 1-8, (2019)

2. Y. Watabe, S. Sassa, "History of land reclamation using dredged soils at Tokyo Haneda Airport", Japanese Geotechnical Society Special Publication, vol.2, no.51, pp1784 - 1789, (2016)

3. Y. D. Wu, R.P. Luo, J. Liu, et al., "Soil disturbance deformation induced by penetration of sampler tube based on transparent soils", Chinese Journal of Geotechnical Engineering, vol.38, no.08, pp1507 1512, (2016)

4. C.R.I. Clayton, A. Siddique, R.J. Hopper, "Effects of sampler design on tube sampling disturbancenumerical and analytical investigations", Géotechnique, vol.48, no.6, pp 847 - 867, (1998)

5. M. M. Ballgh, A. S. Azzouz, C. T. Chin, "Disturbances due to "ideal" tube sampling", Journal of Geotechnical Engineering, vol.113, no.7, pp 739-757, (1987)

6. T. S. Tan, F. H. Lee, P. T. Chong, et al.,"Effect of sampling disturbance on properties of Singapore clay", Journal of Geotechnical and Geoenvironmental Engineering, vol.11, no.128, pp 898-906, (2002)

7. A. L. Jiang, D. Z. Gao, "Analysis of sampling disturbance effected by sampler diameter", Geotechnical Investigation and Surveying, vol.04, pp 13 - 14+38, (2002)

8. H. W. Qin, Y. Chen, L.Y. Gu, "Research on disturbing theory of deepsea sediment sampling", Acta Oceanol. Sinica, vol.29, no.2 pp 92-97, (2007)

9. D. Eyre, "The investigation of tube sampling disturbance using transparent soil and particle image velocimetry", Warwick, Coventry, U.K: Ph.D. dissertation, Univ. (2014)

10. W. R. Zuo, Y. D. Wu, Z. G. Li, et al., "Theoretical analysis of disturbance of soils caused by penetration of soil samplers", Journal of Hohai University (Natural Sciences), vol.37, no.6, pp 702706, (2009)
11. R. Yan, I. Ng, C. Cheuk, "Displacement field around an open-tube sampling, in Proc", 7th Int. Conf. Phys. Modelling Geotech., Zurich, Switzerland, pp 411416, (2010)

12. H. Vuthy, T. Hiroyuki, T. Obara, "Effects of sampling tube geometry on soft clayey sample quality evaluated by nondestructive methods", Soils and Foundations, vol.1, no.90, pp 93-107, (2010)

13. T. X. Liu, W. Chen, L. Ma, et al., "Influence of coring methods on sample bedding in lunar soil drill-sampling", Transactions of the Chinese Society for Agricultural Machinery, vol.45, no.12, pp 355361, (2014)

14. J. Song, "Laboratory simulation test and PFC3D numerical analysis of high clay dredger fill in the consolidation process of step vacuum preloading", Changchun: Jilin University, (2011)

15. C. Shi, Q. Zhang, S. N. Wang, "Numerical simulation techniques and applications of PFC5.0", Beijing: China Architecture \& Building Press, pp 176-179, 404-409, (2018)

16. H.Y. Lei, T. Y. Wang, Z. P. Zhang, et al., "Macroand meso-analysis of newly formed highly viscous dredger fill under vacuum preloading using particle flow theory, Journal of Jilin University(Earth Science Edition), vol.47, no.06, pp1784-1794, (2017)

17. H. T. Liu, X. H. Cheng, "Discrete element analysis for size effects of coarse-grained soils", Rock and Soil Mechanics, vol.30, no.S1, pp 287-292, (2009)

18. T. X. Liu, "Research on lunar soil drilling dynamics based on the on the discrete element method", Harbin: Harbin Institute of Technology, (2015)

19. R. P. Luo, Y. D. Wu, J. Liu, et al., "Tests on transparent soil for soil disturbance deformation induced by sampler penetration", Chinese Journal of Geotechnical Engineering, vol.39, no.S1, pp 64-68, (2017)

20. Shogaki, Takaharu, "Mechanism of sample disturbance caused by tube penetration: Model tests on Toyoura sand", Soils and Foundations, vol.4, no.57, pp 527-542, (2017)

21. D. W. Tang, X. W. Gao, D. M. Zhao, et al., "Analyses of sampling disturbance of the lunar surface in direct push sampling method", IEEE Access, vol.6, pp 48656-48663, (2018) 